\title{
Complex nature of humanitarian crisis: Unique dynamics of civil military relations in Nepal
}

\section{Ratindra Khatri}

\section{Abstract}

The Nepali Army in its vital role in humanitarian assistance and disaster response operation in Nepal receives reputation the world wide. Nepal is prone to disaster risk and the majority of people are living in vulnerable situation. Every year Nepal is facing different types of disasters that caused massive loss of lives and properties. Nepal has not been able to prepare any other viable alternatives in the civil society, so there is no other choice than utilizing militaryor security forces during any disasters. The Nepali Army has vast inbuilt resources to mobilize its troops effectively in any parts of the country. However, timely and effective disaster response is very difficult due to numerous constraints and complexities. Difficult terrain, limited road communication, inadequate resources and insufficient response capacity are prime reasons that make response operations very challenging. The Army together with other security agencies is performing role as per the given mandate articulated in act, rules, framework and guidelines. In this situation, building civil-military coordination mechanism can be an effective means to respond to the disaster. As a matter of fact, a comprehensive disaster army should continue dialogue, training and exercise with foreign militaries for better understanding and learning through experience. Despite the Nepali Army's spectacular capability to disaster response, there is a debate whether the military is a right institution to involve in the humanitarian response operations. However, keeping in mind Nepal's reality without compromising primary role of national sovereignty, territorial integrity and national independence, the Nepali Army should enhance its capability to save lives and property from disasters and hazards.

Keywords: Nepali Army, humanitarian assistance, disaster response, disaster management, Civil-Military coordination, $\mathrm{s}$

\section{Introduction}

Nepal, located in the area where the Indian and Eurasian Plates hit, is one the most frequent earthquake occurrence areas in the world (JIACA, 2018, p. i). Besides, the country is plagued by many recurrent hazards, such as floods, landslides, avalanches, earthquake, thunderstorm, windstorm, cloudburst, lightening, hailstone, drought and different types of epidemics. Geographically, Nepal lies in a rugged and challenging terrain. Developing infrastructures in such types of terrain is a daunting task, as its cost is very high for an underdeveloped country like Nepal. Inhabitants mainly from remote areas are deprived of basic facilities. Maintaining access to these areas to effectively respond to disasters in this terrain remains a genuine problem in the context of Nepal. Humanitarian Assistance and Disaster Response Operation (HADR) has become the Nepali Army's core 
competence with outstanding performances in saving lives and property home and overseas over centurie.

In Nepal, natural disaster management consistently focuses on response operations, which was restricted to rescue and relief. It is generally understood that disaster management is an exclusive responsibility of the Nepali Army (NA). Whenever there is any type of emergency, NA is called for rescue and relief assistance. An established security institution of Nepal, NA with its strong military capability and sufficient resources has been applauded for its efficient and effective response to disasters over decades. In Nepal, NA sustains sufficient resources in terms of human capital, transportation, emergency medical assistance, communication and, on top of that, a disciplined force functioning on a strong chain of command.

From the beginning of the twenty-first century, the concept of Disaster Risk Reduction (DRR) was developed and many other civilian stakeholders emerged. Most of them are working in term of preparedness, and whenever an actual disaster hits the country, they are involved in response, relief and recovery operations. Under the coordination of the Ministry of Home Affairs (MoHA), NA has developed a unique relationship with civilian agencies to efficiently respond to disaster.

\section{Disaster complexity in Nepal}

In the present context of Nepal, it is unlikely that the Nepali Army would need to respond to a complex emergency while complexity of disasters is common phenomenon. Nepal's landscape, which is predominantly composed of hills and steep mountains, combined with fragile geological formations and heavy monsoon rainfall, leads to a wide range of geological and hydro-meteorological hazards affecting the country. In addition, Nepal's geological characteristics together with torrential rain during rainy season often results in landslides, debris flows, and floods (UNISDR, 2015, p. 2). The people living in the mountain regions are exposed to different types of hazards. The mountain ranges in Himalaya are young with unstable geology, steep slopes and unpredictable climate. As a result, the region is highly susceptible to natural hazards such as floods, flash floods, landslides, avalanches and earthquakes. Ultimately, when these hazards convert into a disaster, they have substantial impact in populated areas. Responding to the multitude of hazards is indeed a complex job in Nepal. Reaching congested locations in remote areas has become difficult without concrete roads, foot trails and airstrips.

\section{Legal provision of disaster response}

Prior to the enactment of the Natural Disaster (Relief) Act, 1982, natural disasters were responded at the moment they occurred. We had neither pre-disaster preparedness nor post disaster mitigation measures. Disasters were often treated as acts of god and as a scourge. All forces and resources were used on an ad hoc basis to alleviate the misery brought to the communities (Pradhan, 2007, p. 37). In that backdrop, the Nepali Army in support of the Nepal Police was the major force at the local level. Following the enactment of the Act of 1982, public awareness to disaster response was created. The Act had a provision of NA's membership in search and rescue committees from the central to local level (MoHA, 1982). The National Disaster Response Framework (NDRF) - 2013 highlighted NA as one of the major actors to provide responsibility to establish a Multi-National Military 
Coordination Center (MNMCC) (MoHA, 2013). Based on the same provision, NA took responsibility of coordination between international military and search and rescue assets during Operation 'Sankat Mochan' responding to the 2015 Gorkha Earthquake (Nepali Army, 2015, p. 9). See in Figure A about coordination mechanism with Foreign Military during the Nepal Earthquake 2015.

Civil Military Coordination Mechanism for International Response

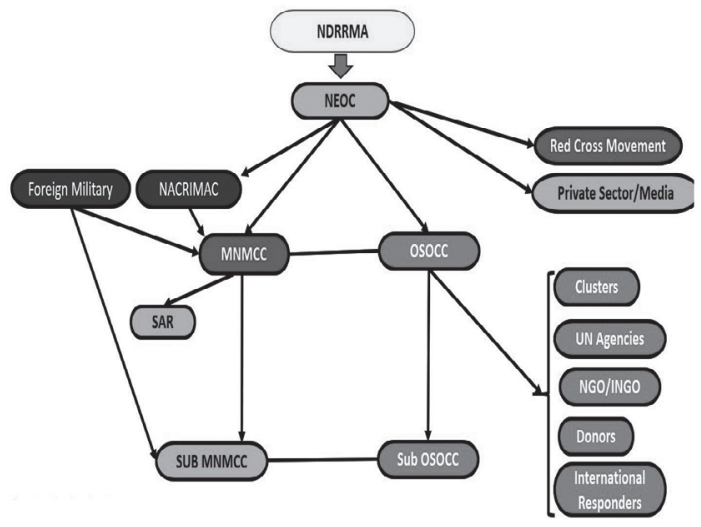

Figure A

Moreover, NA's rigorous engagements in almost all disasters are in the capacity of a first responder. Immediately after the earthquake, NA established the MNMCC in order to expedite the systematic mobilization and coordination of international search and rescue teams in the form of multinational military assistance (CFE-DM publication spring, 2016, p. 16).

Article 6.6 of the revised version of the NDRF 2018 stated that "For search, rescue and relief operations, under the leadership of Chief Executive Officer of the Authority a search and rescue command post will be established at the National Emergency Operation Center (NEOC). The command post shall consist of Joint Secretary from Disaster Management of Ministry of Home Affairs, Director of Disaster Management, Nepali Army and
Head of Disaster Management Division of Nepal Police and Armed Police Force Nepal. The NA takes the command of the Search and Rescue Operation"(MoHA, 2019).

\section{Inherent capability of the Nepali Army}

NA is dedicated to National Security, territorial integrity and sovereignty of Nepal. That is its primary duty. However, as a peacetime engagement without compromising its primary role it is committed to various secondary roles as well. Among them disaster management is one of the important roles. The army has already developed a Directorate of Disaster Management designated for this role with two disaster management battalions and a Disaster Management Training School. Apart from these dedicated troops, the entire NA's units are ready to respond to disasters in their respective area of operations.

The NA has certain inherent characteristics that help them effectively respond to crises in any type of disasters, which are briefly summarized below:

1. NA is a readily deployable force; it remains on 24-hour standby, so that it can be deployed immediately to respond to disasters.

2. NA is physically present in all 77 districts to cover designated areas of responsibility.

3. The army is self-sustained for operational aspects, effective to manage institutional logistics as well as additional supports as required.

4. NA by its nature has core competence to respond to crises with credible instances of rescue and operation home and abroad.

5. NA has unique and critical capability to perform multiple tasks, roles and responsibilities at the same time. 
6. NA's discipline is considered an exemplary institution in local and global spheres.

7. NA has capability to work in complex and difficult geographically terrain. Nepal is a highly rugged and difficult country, and the NA personnel are well trained to maneuver against adverse situations.

8. NA should always be prepared to save lives and property during disasters since Nepal does not have a strong credible alternatives to rescue operation so far.

The Oslo Guideline is the prime document that facilitates foreign military to deploy in friendly country for Humanitarian Assistance and Disaster Response operations. The NA personnel have developed excellent working relationships with many foreign militaries, through joint training, planning, exercises and activities. Some of the activities that the NA undertakes include Disaster Response Exchange and Exercise (DREE) and Tempest Express. This relationship is a part of the peacetime engagement focusing on HADR operations. These foreign military institutions normally have the following capacities:

1. Heavy airlifting capabilities

2. Emergency medical support with mobile surgical hospital capability

3. Air Traffic Management

4. Technical Assistance

5. Engineering Support for debris clearance and critical infrastructure repairing.

6. Logistics Support

7. Search and Rescue

8. Relief support such as water purification and utilities

\section{The NA's responses to disasters}

NA has been playing a significant role in HADR operations in Nepal over centuries. NA is the national force capable and alert to respond natural and manmade disasters in the country through search, rescue and relief. NA has been contributing in protecting lives and property by mobilizing its capable and trained force at times of disaster. NA has done appreciable work in various natural calamities (MoHA, 2016).

In response to the 2015 April devastating earthquake, NA deployed troops throughout the affected areas. Ninety percent of the available troops were deployed on the ground. Total 66,069 were involved, out of which 52,870 were in 594 sites across the 14 most earthquake-affected districts. Teams deployed in the areas were capable of medical response, establishment of relief distribution points and preparation of helipads (Nepali Army, 2015, p. 34).

NA had another unique opportunity to support people in shocking disasters in the neighborhood and abroad. For an example, the Nepali Army personnel were deployed in the UN Mission in Haiti (MIUSTAH) from the beginning. When a devastating earthquake stuck, a couple of the Nepali Army battalions were engaged in operations in the mission areas. As a survivor, from the first minute of disaster, troops were involved in Search and Rescue operations. Throughout the year, NA's troops were involved in different activities of disaster response operations. This columnist was also one of the survivors and responders of the Haiti Earthquake - 2010 in the capacity of Chief Military Personnel Officer of the Mission Headquarter and National Contingent Commander of Nepali Contingent. 


\section{Unique dimension of civil-military coordination}

NA is able to establish a unique relation with sister organizations and other civilian actors involved in the process. The Nepal Police always remain as a supporting force and the Armed Police Force, is also mandated with the responsibility of disaster management in the same manner by the Government of Nepal. For command and coordination, the Ministry of Home Affairs is designated as an apex body. The new act of disaster risk reduction and management has included National Investigation Department (NID) and Provincial Police in the group of 'security agencies' to respond to crises in Nepal (MoHA, 2019, p. 56).

The modern concept of disaster management emphasizes to preparedness, response, recovery and mitigation as major periods of the disaster cycle. When the concept of Disaster Risk Reduction was initiated in Nepal, the Humanitarian Community started playing an effective role in the humanitarian space of Nepal. This community, which consists of domestic and international agencies and organizations, primarily intends to provide humanitarian aid, assistance, relief, development support and human rights advocacy. It includes small local relief societies, large International NonGovernmental Organizations (INGOs), and International Organizations (IOs). Also included are the International Committee of the Red Cross (ICRC), and the International Federation of Red Cross and Red Crescent Societies (IFRC), as well as the National Red Cross and Red Crescent Societies (OCHA, 2010, p. 23). The United Nations Resident Coordinator normally acts as Humanitarian Coordinator (IASC, 2007).
In case a disaster has caused a colossal loss of lives and property; nationally available internal means and resources available in local and national levels can be inadequate. Moreover, the Government of Nepal (Council of Ministers) may appeal for an International Assistance through the UN Resident Coordinators Office. That includes military assistance from their immediate neighbours and friendly countries overseas. During the time of disaster, as per the direction of the Executive Committee and in coordination with the Authority, the NA can establish the Multi-National Military Coordination Center (MNMCC) to mobilize international search, rescue and relief assistance. Within the frame of revised version of the NDRF, NA will establish a Nepali Army Crisis Management Center (NACRIMAC) for HADR operations (MoHA, 2019, p. 48). Regarding Foreign Military deployment APC MADRO have developed an overarching guideline for the Asia Pacific Region: "The sovereignty, territorial integrity and national unity of States must be fully respected in accordance with the Charter of the United Nations. In this context, humanitarian assistance should be provided with the consent of the affected country and in principle on the basis of an appeal by the affected country" (MoHA, 2019, p. 48). Further APC MADRO gave emphasis on "foreign military assets involved in international disaster response operations remain under their own national command and control, operating in support of the Affected State. In addition, foreign military assistance should be provided at no cost to the Affected State" (OCHA, 2010, p. 20).

Broadly, NA needs to coordinate with the following components for the purpose of HADR operations: 


\section{Civil Military Response in 2015 Earthquake}

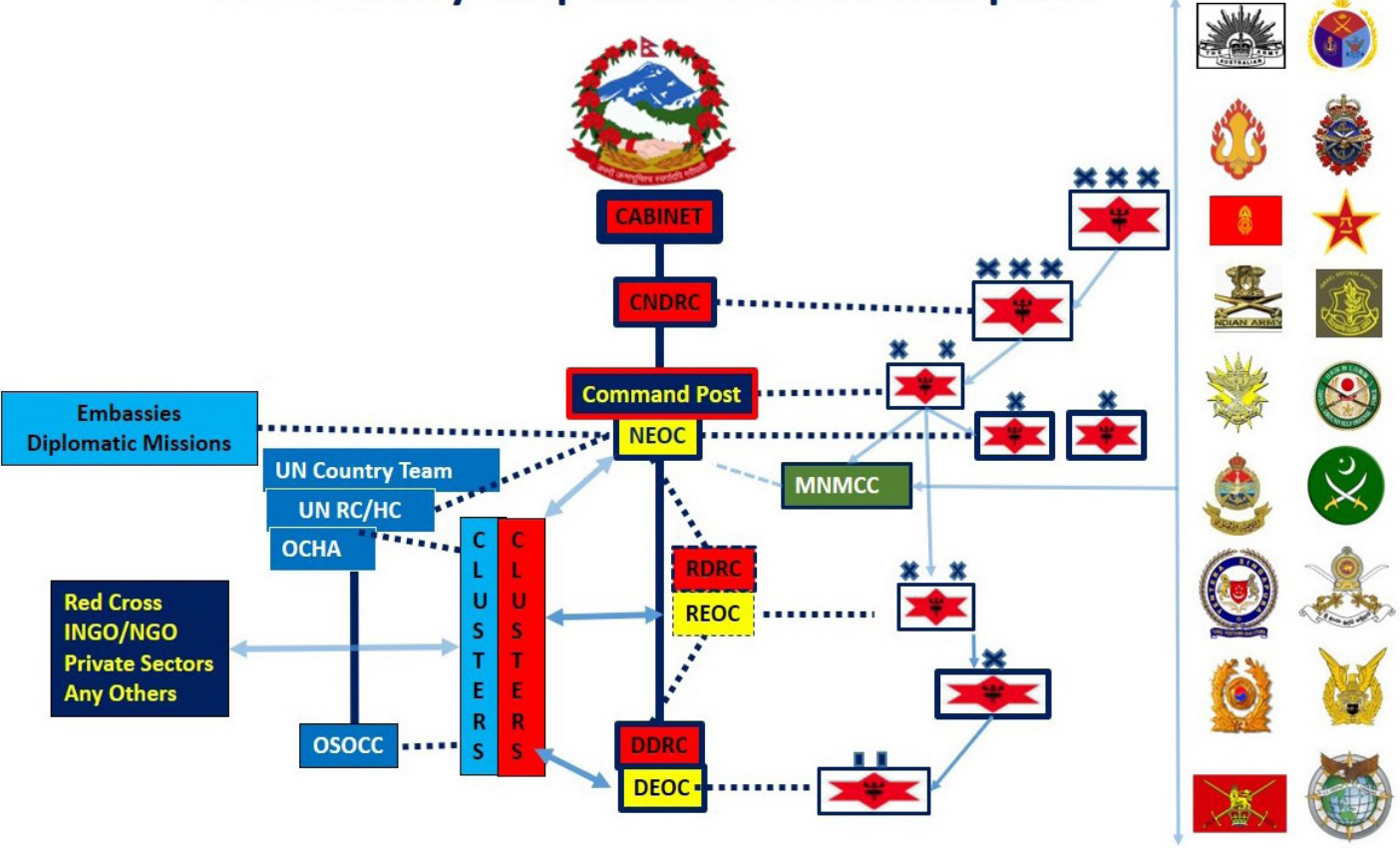

1. Government ministries, departments and other parastatal agencies

2. Sister organizations, including Nepal Police, Armed Police Force, National Investigation Department and Provincial Police

3. Foreign Militaries through MNMCC

4. Humanitarian Communities, such as UN Agencies, NGOs and INGOs

5. Bilateral cooperation with International Friendly countries through Defense attaché or designated focal person

6. Donor community

7. Red Cross and Red Crescent movement

8. Private Sectors and Civil Societies

9. Media

10. Between different arms and services within NA
Military assistance can be divided in three categories based on the degree of contact with the affected population. These categories are important because they help concerned agencies define which types of humanitarian activities might be appropriate to provide support (OCHA, 2007, p. 93),

1. Direct support - face to face

2. Indirect support - at least one-step gap from the population

3. Infrastructure support - providing general service such as critical repair.

\section{Issues and challenges}

Despite NA's significant role in HADR operations, we expose the key challenges in the following:

1. Without adequate resources affectivity of army cannot be maintained, 
therefore, certain equipment and resources need to be provided at all levels.

2. Lack of understanding of each other's roles, mandate, responsibilities and tasks, the result will not be in perfect shape. Joint planning, training and exercise are required to cover this gap.

3. Lack of clarity of its role as per the given mandate to other stakeholders.

4. Social media is a double-edged sword, if it goes the wrong way, it can tarnish the image of NA very badly and the actions may not be seen in the right way.

5. Since an international practice army considered the last resort to mobilize in the HADR operations. Due to various realities and constraints, the NA has a role to play from the beginning. When the army is seen in a lead role, some humanitarian stakeholders may not feel comfortable to work in the same humanitarian environment.

6. Unhealthy competition and duplication of work may sometime hinder the idea of complimenting each other's work.

7. Personal bias of individuals involved in same humanitarian space.

8. Gap on communication channels and information dissemination prohibit sharing of resources at times of need.

9. Adherence to the Humanitarian Principles, especially during complex emergency (OCHA, 2007, p. 12)

- Humanity - human suffering must be address

- Neutrality - must not take sides
- Impartiality - must be on basis on need alone, not by any other vested reason

- Operational Independence - must be autonomous

\section{Way forward}

Many aspects of Disaster Risk Management are gradually developing in the country. Enactment of the new National Disaster Risk Reduction and Management Act and implementation of Disaster Risk Reduction and Management Rule, DRR Strategic Action Plan, DRR National Policy, the revised version of the National Disaster Response Framework are key developments on policy, guidelines and mechanisms. However, many documents are yet to be developed. One of the key needs is hazard-based risk assessment of the entire country to provide information on the need and priority for an integrated disaster management process.

Working to increase the effectiveness of coordination between the NA and domestic civil agencies improves Nepal's disaster response capabilities. It can also address Nepal's key areas of vulnerability. To promote that cooperation several steps can be taken, including but not limited to (1) conducting applied research, (2) helping to develop enhanced capacity and procedures, and (3) supporting strategic thinking and dialogue (Asian Foundation, 2017).

Military and civil defence assets should be seen as a tool complementing existing relief mechanisms to provide specific support in response to the acknowledged humanitarian gap between the disaster needs that the relief community is being asked to fulfil, and the resources available to meet them (OCHA, 2007 , p. 8). Based on the general perspective 
of OCHA, a series of applied research on civil-military aspects of disaster management are required in Nepal, to create:

1. Opportunity to develop knowledge of each other's mandates, roles, capacities and limitations

2. Clear awareness of the nature of this relationship

3. Common understanding of when and how, as well as how not to, coordinate between the military and the humanitarian community.

4. Capacity of Search and Rescue of NA, Nepal Police and Armed Police Force as per the guideline of International Search and Rescue Advisory Group (MoHA, 2019). Without sufficient resources effectivity cannot be maintained, therefore, a minimum level of resources should be provided.

5. Implement a proactive DRR/DRM plan, program and activities that help to substantially reduce disaster risk. Once risk is reduced, the impact of potential disasters will also be less, hence, intensity of response required will also decrease. In that situation, comparably response operation will be more effective.

6. Maintain trust with all concerned and continue to keep this at the highest level.

\section{Conclusion}

Many other actors understand that the military can play a legitimate, as well as a vibrant role in assisting humanitarian relief efforts. Mainly during the critical phase of response operations the military can save the lives of many people at a time of need. Their involvement can maximize potential benefits to the disaster response system and affected populations. In today's world, the military plays an important role in Humanitarian Assistance, and they should be used effectively at the right time, and the right place. The bottom line to be highlighted is that disaster management is not a business of one agency, and it requires an integrated effort of all stakeholders.

One should understand that NA is best equipped to handle disaster because they have a wide assortment of heavy equipment needed for search and rescue missions, enormous reserve of trained personnel, and common culture of discipline and mission oriented standard operations. Dedication and selfless service towards the people of Nepal and the country is another prime factor.

Since NA is standing as a backbone for disaster response in Nepal, maintaining a high standard of effectiveness is of utmost necessity. Enhancing the capacity of NA's units with more resources and skilled work force is a critical need, which will not only increase the capacity of the NA, but also that of the country.

\section{Reference}

CFE-DM Publication Spring. (2016). Liaison Volume VIII, A Journal of Civil-Military Disaster Management \& Humanitarian Relief Collaboration, Mission First and People Always: The Nepali Army's AAR on Operation Sankat Mochan, Hawaii.

JICA. (April, 2018). The project for assessment of earthquake disaster risk for the Kathmandu valley in Nepal, Final Report, Volume I Summery, Kathmandu.

The Brookings-Bern project on International Displacement. (January, 2011). IASC Operational guidelines on the protection of persons in situations of natural disasters, Washington DC. 
The Asian Foundation. (2017). Disaster preparedness and response during political transition in Nepal: Assessing Civil and Military Roles in the Aftermath of the 2015 Earthquakes, Kathmandu.

Pradhan, B. K. (2007). Disaster preparedness for natural hazards; Current status in Nepal, A report submitted to ICIMOD, Kathmandu.

Ministry of Home Affairs. (1982). Natural calamity (Relief) Act 1982. Singhadurbar, Kathmandu.

Ministry of HomeAffairs. (2013). National disaster response framework, 2019. Kathmandu.

Ministry of Home Affairs. (2019). Revised Version of national disaster response framework. First Amendment 2019. Lalitpur: UNDP Publication.

Ministry of Home Affairs. (2019). Disaster risk reduction and management Act 2017 and Disaster Risk Reduction and Management Rules 2019. Lalitpur: UNDP Publication.

Ministry of Home Affairs. (July 2018). Disaster risk reduction strategic action plan 2018-2030, Kathmandu: UNDP Publication.

Ministry of Home Affairs. (2019. Revised Version of national disaster response framework, First Amendment 2019. Lalitpur: UNDP Publication.
Ministry of Home Affairs. (April, 2016). The Gorkha earthquake - 2015. Experience and learning. Lalitpur: UNDP Publications.

Nepali Army. (2015). The Nepalese Army in the aftermath of the Gorkha earthquake of 2015. Experiences and Lessons Learned. Bhadrakali, Kathmandu

OCHA. (November 2007). Oslo guidelines, Guidelines on the use of foreign military and civil defence assets in disaster relief, revision 1.1, United Nation, Geneva.

OCHA. (2007). UN-CMCoord field handbook (v.1.)) 101 Series, United Nations, Geneva.

OCHA. (October 2010). Asia Pacific regional guidelines for the use of foreign military assets in natural disaster response operations, Geneva, United Nations.

United Nations International Strategy for Disaster Reduction UNISDR. (June 2, 2015). 25 April 2015 Gorkha earthquake disaster risk reduction situation report DRR sitrep 2015002, https://www.unisdr.org/files/44592 gorkhaearthquakedisasterriskreducti.pdf 